\title{
Comparative Evaluation of Intrathecal Use of two Different Doses of Dexmedetomidine Along with Bupivacaine in Lower Abdominal Surgeries
}

\author{
Priyanka Bansal ${ }^{1}$, ML Khatri ${ }^{2}$ \\ ${ }^{1}$ Assistant Professor, ${ }^{2}$ Associate Professor Department Of Anaesthesiology, SGT University, Chandu Budhera, \\ Gurgaon, Haryana. \\ Running Title-Intrathecal Use Of Two Different Doses Of Dexmedetomidine
}

\begin{abstract}
:
Introduction: The addition of adjuvants to local anaesthetics in spinal anaesthesia avoids intraoperative somatic and visceral pain and provides prolonged post operative analgesia. Aim -The present study was designed to determine the dose related effects of intrathecal dexmedetomidine added as adjuvant to $0.5 \%$ hyperbaric bupivacaine on block characteristics, haemodynamics and analgesia potentiating effects. Patients and method-This prospective randomised double blind study included 90 patients undergoing lower abdominal surgeries, who were randomly allocated into three groups of 30 patients each. Group B received $12.5 \mathrm{mg}$ of $0.5 \%$ hyperbaric bupivacaine intrathecally, group D5 received $12.5 \mathrm{mg}$ of $0.5 \%$ hyperbaric bupivacaine and 5 $\mu \mathrm{g}$ of dexmedetomidine, group D10 was given $12.5 \mathrm{mg}$ of $0.5 \%$ hyperbaric bupivacaine and $10 \mu \mathrm{g}$ of dexmedetomidine, all three made upto a total volume of $3 \mathrm{ml}$ with NS. The three groups were compared with respect to haemodynamic parameters, onset and regression of motor and sensory block, duration of analgesia, doses of rescue analgesia required and 24 hours complications. The mean time of onset of sensory block to T10 was (in minutes) group B 11.6 \pm 1.12 , group D5 5.84 \pm 2.02 , group D10- $4.92 \pm 1.23$ ( $p<0.001$ ). Total duration of sensory block was (in minutes) group B 172.61 \pm 24.68 , group D5 268.34 \pm 28.42 , group D10 346.28 \pm 44.8 (p $<0.001$ ). Total duration of motor block (in minutes) group B 150.66 \pm 18.64 , group D5 268.44 \pm 24.85 , group D10 $322.9 \pm 49.68$ ( $p<0.001)$. Duration of analgesia (in minutes) - group B 124.01 \pm 8.552 , group D5 194.68 \pm 18.44 , group D10 290.48 \pm 20.64 ( $p<0.001$ ). Conclusion: dexmedetomidine added to hyperbaric bupivacaine intrathecally has a dose dependent favourable effect on the onset and regression of motor and sensory block.

Keywords: spinal, dexmedetomidine, bupivacaine
\end{abstract}

\section{Introduction}

Effective management of perioperative and postoperative pain after lower abdominal surgeries represents an important component of postoperative recovery as it serves to blunt the autonomic, somatic and endocrine reflexes with a resultant potential of decreasing perioperative morbidity. ${ }^{1}$ Multimodel drug analgesia as well as regional techniques have been the most common practice to treat perioperative pain but no method has been identified as yet to specifically block nociception without associated side effects. ${ }^{2}$

Intrathecal block is preferred technique because it is simple and easy to administer, quite economical, has a rapid onset of action with less failure rates and superior level of blockade. ${ }^{3}$ Bupicaine is the most commonly used amide local anaesthetics that has a prolonged duration of action and lower incidence of transient radicular symptoms ${ }^{4}$ but high doses of intraoperative bupivacaine leads to myocardial depression, dysrhythmias and heart blocks. ${ }^{5}$

Various adjuncts such as opioids, epinephrine, neostigmine, magnesium, midazolam, ketamine and clonidine have been added to intrathecal local anaesthetics to prolong analgesia and accelerate functional recovery. ${ }^{6}$

Dexmedetomidine is an s enantiomer of medetomidine, a highly selective $\alpha 2$ adrenoceptor agonist with hypnotic, sedative, anxiolytic, opioid sparing and analgesic properties without producing significant respiratory depression. ${ }^{7,8}$ It acts by blocking release of norepinephrine at locus ceruleus and exerts its analgesic action both at spinal and sensory levels. ${ }^{9}$

Addition of dexmedetomidine to spinal bupivacaine produces shorter onset of motor block and a prolongation in the duration of motor and sensory block with preserved haemodynamics and minimal side effects. ${ }^{10}$ Previous studies have described the intrathecal use of dexmedetomidine in a wide range $(2-15 \mu \mathrm{g}) .{ }^{11,12}$ To compare the subarachnoid block characteristics (onset and duration of motor and sensory block) $5 \mu \mathrm{g}$ and 10 $\mu \mathrm{g}$ of dexmedetomidine was added to $12.5 \mathrm{mg}$ of $.5 \%$ heavy bupivacaine intrathecally. Our study sought to investigate the dose dependent effects of dexmedetomidine on the duration of motor and sensory block, duration 
of analgesia, need for postoperative analgesia and haemodynamic parameters. Also our aim was to find out the dose dependent increase in dexmedetomidine side effects.

Table 1: Demographic profile of group B, D5, D10

\begin{tabular}{|l|l|l|l|l|}
\hline Demographic profile & Group B & Group D5 & Group D10 & p value \\
\hline Mean age in years & $36.32 \pm 10.2$ & $40.23 \pm 11.20$ & $38.11 \pm 8.62$ & 0.738 \\
\hline Weight in kg & $63.42 \pm 10.68$ & $64.66 \pm 8.72$ & $64.12 \pm 9.0$ & 0.862 \\
\hline Sex (\%) & & & & \\
\hline male & $16(53 \%)$ & $17(56 \%)$ & $18(60 \%)$ & 0.990 \\
\hline female & $14(47 \%)$ & $13(44 \%)$ & $12(40 \%)$ & \\
\hline ASA grade & & & & \\
\hline Grade I & $22(73 \%)$ & $24(80 \%)$ & $25(83 \%)$ & 0.638 \\
\hline Grade II & $8(27 \%)$ & $6(20 \%)$ & $5(17 \%)$ & \\
& & & & \\
\hline
\end{tabular}

Table 2: Types Of Surgeries (Lower Abdominal Surgeries)

\begin{tabular}{|l|l|l|l|l|}
\hline & surgery & Group B $(\mathrm{n}=30)$ & Group D5 $(\mathrm{n}=30)$ & Group D10 $(\mathrm{n}=30)$ \\
\hline 1 & Inguinal hernia & 7 & 4 & 5 \\
\hline 2 & Abdominal hysterectomy & 4 & 5 & 2 \\
\hline 3 & Benign prostatic hypertrophy & 3 & 1 & 5 \\
\hline 4 & Umbilical hernia & 5 & 4 & 6 \\
\hline 5 & Haemorrhoids & 3 & 7 & 5 \\
\hline 6 & Hydrocele & 3 & 5 & 4 \\
\hline 7 & Appendicectomy & 5 & 4 & 3 \\
\hline
\end{tabular}

\section{Materials And Methods}

Our study was a randomized, patient and observer blind (double blind), concentration controlled, single centre trial. After obtaining permission from institutional ethics committee written informed consent was taken. A total of 90 patients were randomly allocated into 3 equal groups of 30 each using computer generated random numbers inserted into sealed envelops marked 1-90. Patients having ASA physical status I and II age 20-60 years and of either sex undergoing elective various lower abdominal surgeries under spinal anaesthesia were included in the study.

Exclusion criteria - patient refusal, any known allergy or contraindication to bupivacaine or dexmedetomidine, pregnancy, hepatic, renal or cardiopulmonary abnormalities, alcoholism, diabetes, long term analgesic or anticoagulant therapy, spinal cord deformities, neurological or neuromuscular deficits, paralysis, bleeding diathesis, local skin site infections or patients on $\alpha_{2}$ adrenergic receptor antagonists, calcium channel blockers, ACE inhibitors, morbid obesity (Body weight $>120 \mathrm{~kg}$ ) or height $<150 \mathrm{~cm}$.

A day before surgery a detailed preanaesthetic checkup was carried out. Patients were asked to restrict fluids and solid by mouth atleast six hours before operation. Interpretation of VAS (visual analogue scale) was explained to determine level of analgesia in the postoperative period. This was carried out with $10 \mathrm{~cm}$ line. The first end marked ' 0 ' means 'no pain' and the end marked ' 10 ' means 'worst pain imaginable'.

All patients were clinically examined in the preoperative period, where whole process was explained. On entering the patient in the operating room standard intraoperative monitors like ECG, pulse oximeter, NIBP were attached and baseline parameters (blood pressure, heart rate, respiratory rate) were recorded. The patients were preloaded with lactated Ringer's solution (RL) $10 \mathrm{ml} / \mathrm{kg}$. Technique used was standardized for all patients. Peripheral IV line was secured with $18 \mathrm{G}$ cannula. After preloading with RL and under aseptic preparation, lumbar puncture was performed at L3 - L4 interverteberal space (L2 -L3, in case difficulty occurs) in median approach with $25 \mathrm{G}$ Quinke spinal needle. The patients were randomized into 3 groups B, D5, D10 of 30 patients each using sealed envelope technique. The dose of $.5 \%$ hyperbaric bupivacaine $12.5 \mathrm{mg}$ was identical in all study groups. In group B patients received $12.5 \mathrm{mg}$ of $.5 \%$ bupivacaine which was made upto $3 \mathrm{ml}$ after dilution in $.9 \%$ saline (NS). Group D5 received $12.5 \mathrm{mg}$ of $.5 \%$ bupivacaine and $5 \mu \mathrm{g}$ of dexmedetomidine, total drug volume made upto $3 \mathrm{ml}$ with $.9 \%$ saline (NS). Group D10 received $12.5 \mathrm{mg}$ of hyperbaric bupivacaine and $10 \mu \mathrm{g}$ of dexmedetomidine, total volume made upto $3 \mathrm{ml}$ with $.9 \%$ saline.

The intrathecal drug formula was prepared by a separate anaesthesiologist by a sterile technique who was blinded to the study and block given by a different anaesthetist who also monitored block characteristics and was also blinded to the study groups. PR, RR, BP were monitored every 5 minutes for first 15 minutes then every 10 minutes till the end of surgery and every 30 minutes in the postoperative ward till 1 hour and every 2 hours thereafter.

Incidence of intraoperative hypotension (decrease of systolic BP $20 \%$ from baseline or systolic BP<90) was recorded. Hypotension was treated with oxygen, bolus administration of $250 \mathrm{ml}$ lactated Ringer's solution over 10 minutes, or with intermittent doses of intravenous mephentermine at $6 \mathrm{mg}$. Bradycardia (HR $<50$ beats /minute) and tachycardia (HR>100 beats/minute) were also recorded. Episodes of bradycardia were treated with incremental doses of atropine at $0.3 \mathrm{mg}$ administered intravenously. The total duration of surgery was noted. 
Sensory block was assessed by loss of sensation to pin prick in midline using a $22 \mathrm{G}$ blunt hypodermic needle at 2 minute interval till block reaches T8 at which level surgery was allowed to proceed. Level was assessed at 3 minute interval till no change in level was seen, thereafter every 20 minute interval. Onset of sensory block to T10 dermatome, peak level of sensory block and duration of sensory block (regression to S1 dermatome) was noted.

Degree of motor block was assessed by means of James modified Bromage score (0-no resistance, able to raise aleg straight against resistance, 1-able to raise leg straight but able to flex knee, 2- unable to flex knee but with free movement of feet, 3-unable to move leg or feet). Onset time to reach Bromage 3 and time taken for regression to bromage 0 were noted.

All durations were calculated by taking the time of drug administration intrathecally as time 0 . Analgesia was monitored by using VAS score. VAS was recorded 5 minutes before spinal, at start of surgery and then every 15 minute interval till the surgery was over. Postoperatively VAS was recorded half houly for first hour then 1 hourly for 12 hours, and then 3 hourly for next 12 hours till 24 hours. When patient had VAS> 3 rescue analgesia in the form of diclofenac sodium $75 \mathrm{mg}$ intramuscular (I/M) or when needed inj. Tramadol 50 mg slow IV was given. Time to first dose of rescue analgesia, number of doses of rescue analgesia and the time at which it was repeated was recorded in all groups. The time at which patient demanded first dose was the primary end point of this study because at this point the effect of spinal anaesthesia has weaned off.

In case of failed spinal block patients were given general anaesthesia and these patients were excluded from the study. The quality of surgical analgesia was assessed and graded as: Excellent: if no supplemental drugs were required, Good: only one analgesic required, Fair: if more than one analgesic required, Poor: GA required. If full surgical anaesthesia was not achieved then inj. tramadol 50-100 mg IV was given as supplementary analgesia during surgery. Patients were monitored for sedation every 10 minute interval for first 30 minutes and then every 15 minute interval till completion of surgery. Following sedation score was used 0: no sedation

1: patient somnolent but responding to verbal commands

2: patient somnolent not responding to verbal commands

3: patient somnolent and not responding to verbal commands and manual stimulation.

Our primary outcome after completion of surgery was to compare the duration of motor and sensory block, secondary outcome was to observe the onset of motor and sensory block, level of sensory block achieved, haemodynamic parameters, duration of motor and sensory block, time and dosage of analgesic used, to compare pain scores among the three groups and any side effects noted throughout the study period and 24 hours postoperatively.

Any side effects or complications like hypotension and bradycardia headache, dry mouth, nausea, vomiting, local anaesthetic toxicity, backache and urinary retension were noted in these 24 hours. This was secondary end point of our study.

\section{Statistical Analysis}

The statistical analysis of the data was done by using SPSS evaluation version 20 (statistical package for social sciences). The data was expressed as either mean or standard deviation for number and percentages. The demographic data of patients was studied for each of the three groups. Continuous covariates (age, duration of surgery, height, weight) were compared using analysis of variance (ANOVA). For categorical covariates (gender, ASA class) chi square test was used with $\mathrm{p}$ value reported at $95 \%$ confidence interval.

For the time to reach T10 dermatome, Bromage 3 scale and regression of block to S1 dermatome and Bromage 0, time taken to rescue analgesia ANOVA test followed by Tuckey's multiple post hoc test was used. The level of significance used was $\mathrm{p}<0.05$.

The total sample size calculated was 42 (14 patients in each group). Power analysis using the following parameters was carried out $(\alpha=0.05, \beta=0.8)$ total duration of analgesia and time to bromage scale 0 . We increased the total number of patients to increase the power of study. $p$ value $<0.01$ was considered highly significant. Post hoc power analysis was carried out using a power and sample size calculator. The cut off value for power analysis was taken as at least $80 \%(\beta=0.8)$. The effective size/power was calculated for duration of analgesia $(\beta=1)$ and the duration of motor block $(\beta=1)$ determined as $>80 \%$. Thus the post hoc assessment of effective size justified the sample size.

Table 3: Sensory And Motor Block Characteristics

\begin{tabular}{|l|l|l|l|l|}
\hline characteristic & Group B & Group D5 & Group D10 & p value \\
\hline $\begin{array}{l}\text { Onset time to T10 (in } \\
\text { minutes) }\end{array}$ & $11.6 \pm 1.12$ & $5.845 \pm 2.02$ & $4.92 \pm 1.23$ & $<0.001$ \\
\hline $\begin{array}{l}\text { Max. level of sensory } \\
\text { block }\end{array}$ & T6 & T6 & T6 & $>.5$ \\
\hline
\end{tabular}


Comparative Evaluation of Intrathecal Use Of Two Different Doses of Dexmedetomidine...

\begin{tabular}{|l|l|l|l|l|}
\hline $\begin{array}{l}\text { Time to max level of } \\
\text { sensory block (in } \\
\text { minutes }\end{array}$ & $17.64 \pm 2.01$ & $10.6 \pm 4.65$ & $8.02 \pm 0.412$ & $<0.001$ \\
\hline $\begin{array}{l}\text { Time to regression of } \\
\text { block to S1(in minutes) }\end{array}$ & $172.61 \pm 24.68$ & $268.34 \pm 28.42$ & $346.28 \pm 44.8$ & $<0.001$ \\
\hline $\begin{array}{l}\text { Onset of motor block to } \\
\text { Bromage 3 (in minutes) }\end{array}$ & $18.02 \pm 0.96$ & $12.96 \pm 2.64$ & $9.42 \pm 2.36$ & $<0.001$ \\
\hline $\begin{array}{l}\text { Duration of motor block } \\
\text { (minutes) }\end{array}$ & $150.66 \pm 18.64$ & $268.44 \pm 24.85$ & $322.94 \pm 9.68$ & $<0.001$ \\
\hline $\begin{array}{l}\text { Duration of } \\
\text { analgesia(minutes) }\end{array}$ & $124.01 \pm 8.552$ & $194.68 \pm 18.44$ & $290.48 \pm 20.64$ & $<0.001$ \\
\hline $\begin{array}{l}\text { Mean total doses of } \\
\text { rescue analgesia }\end{array}$ & $2.84 \pm 0.268$ & $1.92 \pm 0.268$ & $1.28 \pm 0.408$ & $<0.01$ \\
\hline
\end{tabular}

Table 4: Surgical Characteristics, Adverse Effects And Treatment

\begin{tabular}{|l|l|l|l|l|}
\hline & Group B & Group D5 & Group D10 & p value \\
\hline Total IV infusion (in ml) & $1100 \pm 148.2$ & $921 \pm 216.4$ & $1028 \pm 284.3$ & .32 \\
\hline Duration of surgery(in minutes) & $54.66 \pm 5.64$ & $43.84 \pm 11.68$ & $50.64 \pm 3.3$ & .64 \\
\hline Bllod transfusion (no. of patients) & 1 & 2 & 1 & .74 \\
\hline Additive analgesia (no. of patients) & 2 & 1 & 0 & .56 \\
\hline Nausea/vomiting (no. of patients) & 1 & 0 & 1 & .34 \\
\hline Bradycardia & 1 & 1 & 1 & .12 \\
\hline Hypotension & 2 & 1 & 3 & .64 \\
\hline Atopine & 0 & 1 & 1 & .36 \\
\hline Mephentermine & 1 & 2 & 1 & .23 \\
\hline Shivering & 2 & 1 & 0 & .56 \\
\hline
\end{tabular}

\section{Results}

All patients (90) completed the study, there was no statistical difference in the patients demographic variables or duration of surgery as shown in table 1. Table 2 shows the number of patients in each group undergoing different types of lower abdominal surgeries. The number of patients under each type of surgery performed were similar amongst the groups thereby keeping the comparison unbiased.

The sensory and motor block characteristics are shown in table 3. The mean time required for onset of sensory block to T10 dermatome in group D10 $(4.92 \pm 1.23)$ was more rapid than either group D5 or B. Also onset of sensory block to T10 was more rapid in group D5 than in group B $(\mathrm{p}<0.001)$. The maximum upper level of sensory block achieved in group B or D5 was T6- T8 dermatome with a median value of T6 and group D10 it was T5-T8 dermatome with a median of T6 dermatome, which was comparable in all three groups. However the maximum level of sensory block was achieved earlier in group D10 $(8.02 \pm 0.412)$ than in group D5 or B. Also it was earlier in group D5 than in group B and the difference was highly significant $(\mathrm{p}<0.001)$.

The addition of dexmedetomidine has significant effect of sensory block. The mean time taken for regression of sensory block to $\mathrm{S} 1$ dermatome was much more prolonged in D10 (346.28 \pm 44.8 minutes) than in group D5 (268.44 \pm 24.85 minutes) and this was much longer in comparison to group B (150.66 \pm 18.64$)$. The prolongation in time to regression in group B vs group D5, group B vs group D10 and group D5 vs group D10 was highly significant statistically by Tuckey's test $(\mathrm{p}<0.001)$.

Complete motor block was achieved earlier in group D10 and group D5 than group B and it was much earlier in group D10 than in group B. It was $9.42 \pm 2.36$ minutes in group D10 and 12.96 \pm 2.64 minutes in group D5 and $18.02 \pm 0.96$ minutes in group B. Thus the difference was statistically highly significant $(\mathrm{p}<0.001)$. Statistical analysis by ANOVA and Tuckey's showed that the total duration of motor block was significantly prolonged in group D10 and D5 as compared to group B. Similarly it was more prolonged in group D10 as compared to group D5 and the difference was highly significant $(p<0.001)$.

Patients remained pain free for a longer duration in group D10 and D5 than in group B and requirement for first dose of rescue analgesia was significantly prolonged after addition of dexmedetomidine. VAS score was less than 3 in all three groups during intraoperative period and none of the patients required supplementary analgesia. In group B VAS started increasing and was $>3$ in second and third hour postoperatively and first dose of rescue analgesia (I/M diclofenac) was given. Thereafter VAS was $<3$ and patients were pain free. VAS again increased to $>3$ in $9^{\text {th }}$ and $10^{\text {th }}$ hour and IV tramadol was given. The second dose of injectable diclofenac was given in the $13^{\text {th }}$ hour.

In group D5 first dose of rescue analgesia (VAS $>3$ ) was given in $3^{\text {rd }}$ to $4^{\text {th }}$ hour and second dose in $14^{\text {th }}$ to $15^{\text {th }}$ hour and thus the difference is highly significant in comparision with group B.

In group D10 the first dose of rescue analgesia was given in $5^{\text {th }}$ to $6^{\text {th }}$ hour and second dose at $17^{\text {th }}$ to $18^{\text {th }}$ hour. None of the in groups D5 or D10 required injectable tramadol. When Tuckey's post hoc analysis was applied the difference in duration of analgesia in between group D5 and group D10 was highly significant which confirmed that the increase in the duration of analgesia after addition of dexmedetomidine is dose dependent. 
The total number of rescue analgesia doses required at 24 hours postoperatively were also significantly less in group D10 as shown in table 3.

Haemodynamic parameters remained stable and were comparable in both groups at all measured intervals (fig 1). Episodes of hypotension (group B-2, group D5- 1 and group D10-3 patients) were treated with oxygen and supplemental fluid intravenously. Only one patient required IV mephentermine.

The sedation score was comparable in both groups at all intervals for 24 hours. Most of the patients $(25$ in group B, 23 in group D5, 19 in group D10) had a sedation score of 0. 5 patients in group B, 5 in D5 and 9 in D10 had a sedation score of 1.1 patient in group B 2 in D5 and 2 patients in group D10 had a sedation score of 2. Incidence of nausea and vomiting was comparable. Only 1 patient in group B and D10 had nausea which was relieved with injection ondansetron (100 mg IV). The quality of surgical analgesia was excellent in all patients in all 3 groups and none of the patient required any supplemental analgesia during the intraoperative period. 24 hours and 2 weeks following discharge follow up did not show any neurological impairement related to spinal anaesthesia such as back, buttock or leg pain or headache or any new neurological deficit.

\section{Discussion}

Postoperative pain and its complications can be attenuated with an appropriate perioperative analgesic regimen. Regional anaesthesia for any major lower abdominal surgery has long been provided by central neuraxial blockade. Dexmedetomidine- a highly selective $\alpha 2$ adrenergic agonist has analgesic, sedative and anaesthetic sparing effects when used in systemic route without any significant respiratory depression. Use of dexmedetomidine as an adjuvant mixed with local anaesthetic has been performed with neuraxial anaesthesia in both adult and paediatric patients.

The mechanism by which intrathecal $\alpha 2$ adrenoceptor agonists prolong motor and sensory block of local anaesthetics is not well known. It may be additive or synergistic effect secondary to different mechanism of action of local anaesthetics. The local anaesthetics act by blocking $\mathrm{Na}^{+}$(sodium) channels whereas $\alpha$ adrenergic agonists are said to act by binding to presynaptic c fibres and post synaptic dorsal horn neurons. ${ }^{12,13}$ Their analgesic action is a result of depression of release of $c$ fibre transmitters and hyperpolarization of postsynaptic dorsal horn neurons and prolonged motor block might be caused by direct impairement of excitatory iminoacid release spinal interneurons. ${ }^{14}$

In this prospective, randomized, double blind study in patients scheduled for lower abdominal surgery, we compared the dose dependent effect of $5 \mu \mathrm{g}$ and $10 \mu \mathrm{g}$ of dexmedetomidine added to $12.5 \mathrm{mg}$ of intrathecal bupivacaine on the onset time and duration of motor and sensory block as well as on the postoperative rescue analgesia required and associated side effects if any. The demographic profile in all three groups which was statistically insignificant $(\mathrm{p}>0.05)$ was quite similar with other research investigations and provided us with a uniform platform to evenly compare the results obtained.

A similar study was conducted by Mustafa et al, in which 66 patients scheduled for urological procedures were randomly divided into 3 groups and given dexmedetomidine $5 \mu \mathrm{g}$ and $10 \mu \mathrm{g}$ along with 12.5 mg of bupivacaine. ${ }^{14}$ Our results are similar and further confirm the fact that when dexmedetomidine is added as adjuvant to bupivacaine in spinal anaesthesia, the prolongation of motor and sensory block occurs in a dose dependent manner that is as the dose of dexmedetomidine is increased more is the duration of motor and sensory block and duration of analgesia. In our study the onset time to highest level was also noted due to level of incision in lower abdominal surgeries. The postoperative analgesia is even more prolonged with $15 \mu \mathrm{g}$ of dexmedetomidine, which may be beneficial in patients undergoing lengthy and complex surgeries, but this dose leads to higher sedation scores which may be undesirable. ${ }^{12}$ We chose $5 \mu \mathrm{g}$ and $10 \mu \mathrm{g}$ of dexmedetomidine in comparison with plain bupivacaine so that in addition to prolongation of analgesia by dexmedetomidine, its dose dependent effect may be confirmed with minimal side effects. ${ }^{15}$

Tarbeehet et al and Jamlia RH et al also found that dexmedetomidine has a dose dependent effect on onset and regression of motor and sensory block and time to rescue analgesia with lower VAS scores and minimal side effects when used as an adjuvant to intrathecal bupivacaine. Similar results were found by halder et al. ${ }^{16,17,18}$

In our study the onset of sensory block was earlier in dexmedetomidine group with much earlier in group D10. Ogan et al showed an earlier significant peak sensory block in dexmedetomidine group compared to other groups. Shukla et al also showed that onset time to peak sensory level was earlier in dexmedetomidine group compared to control group. ${ }^{19}$

A study done by Kanazi et al including 60 patients undergoing transurethral resection of prostrate or bladder tumour under spinal anaesthesia reported shorter onset time of motor block but longer sensory and motor regression times in bupivacaine given with dexmedetomidine $(3 \mu \mathrm{g})$ as compared with bupivacaine alone. They showed that mean time to sensory regression to S1 was $303 \pm 75$ minutes whereas in our study it was longer, which clearly indicate dose dependent effect of dexmedetomidine. 
The regression of motor block to Bromage 0 was $322.94 \pm 9.68$ minutes with higher dose of dexmedetomidine $(10 \mu \mathrm{g})$. Similar results were shown by Kanazi et al. ${ }^{20}$

As regards the first time to require analgesia and total analgesic consumption of diclofenac in 24 hours, group D10 showed asignificant increase in time to first analgesic dose (290.48 \pm 20.64 minutes) and significant decrease in total analgesic consumption. In agreement with our results, Eid and colleagues, showed a significantly longer time to first analgesic request compared to control group. ${ }^{12}$ Ashraf and colleagues also showed a significantly longer time to first analgesic request (3.30 \pm 0.87 hours) compared to control group $90.23 \pm 0.11$ hours).

In the present study, no sedative was given during premedication, and thus most of the patients had sedation score in the range of 0 and 1 at all measured intervals in both groups. It has also been observed earlier that addition of low-dose dexmedetomidine to intrathecal bupivacaine does not lead to higher sedation scores. Patients remained hemodynamically stable in both groups at all measured intervals for $24 \mathrm{~h}$. Dexmedetomidine as an intrathecal adjuvant to bupivacaine in a dose dependent manner does not produce any significant hemodynamic changes and vitals remained stable both intraoperatively and postoperatively.

Further studies are required to rule out any short term or long-term adverse effects of intrathecal dexmedetomidine, although in our study 24 hours follow up showed no significant side effects. Patients only in ASA grade I and II were included in our study. Safety of dexmetomidine therefore needs to be evaluated in patients with known cardiovascular or other comorbidies or in pregnancy. Another limitation being that we limited our dose to $10 \mu \mathrm{g}$ of dexmedetomidine. Further studies are therefore required with higher doses of dexmedetomidine to better know its side effects and limitations. Effect of adding dexmedetomidine to other local anaesthetics like ropivacaine or levobupivacaine in other neuraxial blocks needs further research.

\section{Conclusion}

Finally we do conclude that addition of dexmedetomidine in $10 \mu \mathrm{g}$ dose compared with $5 \mu \mathrm{g}$ dose provides fast onset and longer duration of motor and sensory blockade and also reduced the requirement of postoperative rescue analgesia when used along with hyperbaric bupivacaine $0.5 \%$ in spinal anaesthesia in lower abdominal surgeries.

\section{Bibliography}

[1]. Perlas A, Kirkham KR, Billing R, Tse C, Brull R, Gandhi R, et al. The impact of analgesic modality on early ambulation following total knee arthroplasty. Reg Anesth Pain Med. 2013; 38:334-39.

[2]. Hyllested M, Jones S, Pedersen JL, Kehlet H. Comparative effect of paracetamol, NSAIDs or their combination in postoperative pain management: a qualitative review. Br J Anaesth. 2002; 88:199-214.

[3]. Koller C. On the use of cocaine for producing anaesthesia on the eye. Lancet 1884; 2:990.

[4]. Casati A, Fanelli G, Beccaria P, Aldegheri G, Berti M, Senatore R, Torri G. Block distribution and cardiovascular effects of unilateral spinal anaesthesia by $0.5 \%$ hyperbaric bupivacaine. A clinical comparison with bilateral spinal block. Minerva Anestesiol 1998; 64:307-312.

[5]. Albright GA Cardiac arrest following regional anesthesia with etidocaine or bupivacaine. Anesthesiology 1979; 51:285-287.

[6]. Buvanendran A, Kroin JS Useful adjuvants for postoperative pain management. Best Pract Res Clin Anaesthesiol 2007; 21:31-49.

[7]. Bouaziz H, Hewitt C, Eisenach JC. Subarachnoid neostigmine potentiation of alpha-2-adrenergic agonist analgesia, dexmedetomidine vs clonidine. Reg Anesth 1995; 20:121-127.

[8]. Glynn C, Dawson D, Sanders R. A double-blind comparison between epidural morphine and epidural clonidine in patients with chronic noncancer pain. Pain 1988; 34:123-128.

[9]. Kalso EA, Poyhia R, Rosenberg PH. Spinal antinociception by dexmedetomidine, a highly selective alpha 2-adrenergic agonist. Pharmacol Toxicol 1991; 68:140-143.

[10]. Abdel Hamid SA, El-lakany MH. Intrathecal dexmedetomidine: useful or not? J Anesth Clin Res 2013; 4:1-5.

[11]. Al-Mustafa MM, Badran IZ, Abu-Ali HM ,Al-Barazangi BA, Massad IM, Al-Ghanem SM. Intravenous dexmedetomidine prolongs bupivacaine spinal analgesia. Middle East J Anesthesiol 2009; 20:225-31.

[12]. Hala EA, Shafie MA, yousef H. Dose -related prolongation of hyperbaric bupivacaine spinal anesthesia by dexmedetomidine. Ain Shams J of Anesthesiol 2011; 4:83-95.

[13]. Ishii H , Kohno T , Yamakura T , Ikoma M , Baba H. Action of dexmedetomidine on the substantia gelatinosa neurons of the rat spinal cord. Eur J Neuro sci 2008; 27:3182-90.

[14]. Al-Mustafa MM, Abu-Halaweh SA, Aloweidi AS, Murshidi MM, Ammari BA, Awwad ZM, et al. Effect of dexmedetomidine added to spinal bupivacaine for urological procedures. Saudi Med J. 2009; 30:365-70.

[15]. Gupta R, Bogra J, Verma R, Kohli M, Kushwaha JK, Kumar S. Dexmedetomidine as an intrathecal adjuvant for postoperative analgesia. Indian J Anaesth $2011 \mathrm{Jul} ; 55(4): 347-351$.

[16]. Halder S, Das A, Mandal D, Chandra M, Ray S, Biswas MR et al.; Effect of Different Doses of Dexmedetomidine as Adjuvant in Bupivacaine -Induced Subarachnoid Block for Traumatized Lower Limb Orthopaedic Surgery: A Prospective, Double-Blinded and Randomized Controlled Study. Journal of Clinical and Diagnostic Research, 2014; 8(11): GC01-6.

[17]. Tarbeeh GA, Mohamed MA. Effects of intrathecal bupivacaine-fentanyl versus bupivacaine-dexmedetomidine in diabetic surgical patients. Egyptian J of Anaesth.2013;29:13-18.

[18]. Jamliya RH, Deshmukh V , Rajesh C ,Maliwad J, Shah BJ , Minaxi H.Effect of adding dexmedetomidine in intrathecal bupivacaine versus intrathecal bupivacaine alone on spinal block charecteristics inorthopaedic lower limb procedures. Res $\mathrm{J}$ Pharm Biol Chem Sci 2013;4:1340-1346.

[19]. Shukla D, Verma A, Agarwal A, Pandey HD, Tyagi C. Comparative study of intrathecal dexmedetomidine with intrathecal magnesium sulfate used as adjuvants to bupivacaine. J Anaesthesiol Clin Pharmacol. 2011; 27:495-99. 
Comparative Evaluation of Intrathecal Use Of Two Different Doses of Dexmedetomidine...

[20]. Kanazi GE, Aouad MT, Jabbour-Khoury SI, Al Jazzar MD, Alameddine MM, Al-Yaman R et al.; Effect of Low-Dose Dexmedetomidine or Clonidine on the characteristics of bupivacaine spinal block. Acta Anaesthesiol Scand; 2006; 50:222-7.

Figure 1: Comparison of Preoperative Vitals

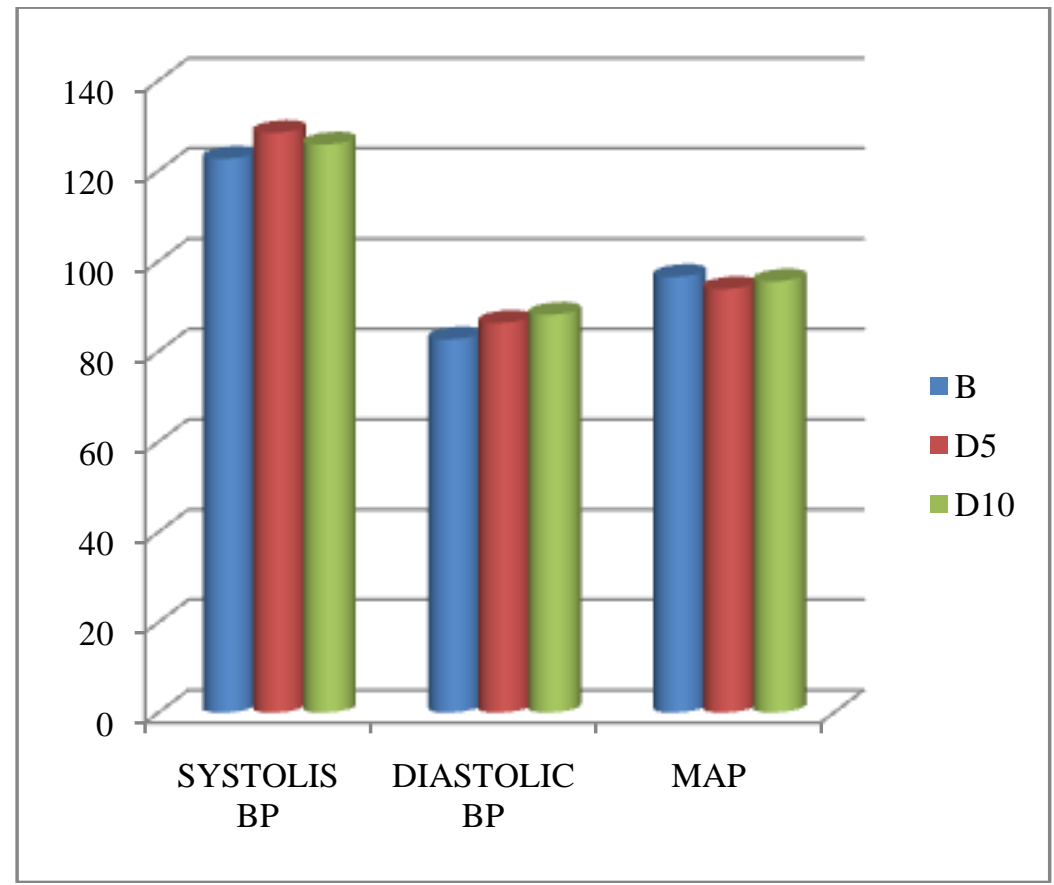

